International Journal of Current Advanced Research

ISSN: O: 2319-6475, ISSN: P: 2319 - 6505, Impact Factor: SJIF: 5.995

Available Online at www.journalijcar.org

Volume 6; Issue 4; April 2017; Page No. 3374-3375

DOI: http://dx.doi.org/10.24327/ijcar.2017.3375.0277

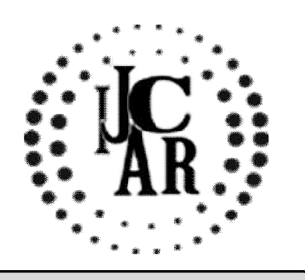

Research Article

\title{
EFFECT OF TIME INDUCED STRESS IN BLOOD PRESSURE
}

\author{
Subeeksha.V.S* and Jothi Priya
}

Department of Physiology, Saveetha Dental College.

\section{A R T I C L E I N F O}

\section{Article History:}

Received $5^{\text {th }}$ January, 2017

Received in revised form $9^{\text {th }}$ February, 2017

Accepted $22^{\text {nd }}$ March, 2017

Published online $28^{\text {th }}$ April, 2017

\section{Key words:}

Education, Army,

Development \begin{abstract}
A B S T R A C T
Aim: To research on the effect of time induced stress in blood pressure

Background: The body produces a surge of hormones when one is in a stressful situation. These hormones temporarily increase the blood pressure by causing the heart to beat faster and the blood vessels to narrow.

Reason: This research is to create awareness on short term stress related spikes in the blood pressure up over time may put one, at a risk of developing long term high blood pressure

Results: The individuals had temporary increase of the blood pressure which indicates prehypertension.
\end{abstract}

Copyright $₫ 2017$ Subeeksha.V.S and Jothi Priya. This is an open access article distributed under the Creative Commons Attribution License, which permits unrestricted use, distribution, and reproduction in any medium, provided the original work is properly cited.

\section{INTRODUCTION}

Stress is body's way of responding to any kind of demand or threat. When someone sense danger, the body's defence mechanism kicks into high gear in a rapid, automatic process known as the "fight-or-flight" reaction, or the stress response.[5] Its just not the routine or negative or traumatic stress, it is also the time that causes stress. Stress comes from time, demands and pressure of the recent past and anticipated time, demands and pressures of the near future.[1] It's been clear for some time that psychological stress is linked to high blood pressure, or hypertension, but the reason is unknown.[3] Situational stress is the most common type of stress. Situational stress is something when a body is subjected to a stress, the body reacts by releasing stress hormones (adrenaline and cortisol) into the blood. These hormones prepare the body for the "fight or flight" response by making the heart beat faster and constricting blood vessels to get more blood to the core of the body instead of the extremities.[6] Constriction of blood vessels and increase in heart rate does raise blood pressure, but only temporarily, when the stress reaction goes away, blood pressure returns to its pre-stress level. Its effects are generally short-lived and disappear when the stressful event is over. But there are cases in which the situation stress can lead to chronic stress, only if the situation stress becomes a routine or habit which in-turn leads to various diseases and disorders including anxiety, depression, digestive problems, headaches, heart disease, sleep problems, weight gain or loss, memory and

*Corresponding author: Subeeksha.V.S

Department of Physiology, Saveetha Dental College. drinking more, exercising less and eating unhealthily - all of which can lead to longer-term increases in blood pressure. The easiest way to reduce stress that can indirectly influence hypertension is to avoid those unhealthy behaviours that contribute to this condition.[3] It's also important to note that while the link between stress and high blood pressure (HBP or hypertension) is still being studied because there's no proof that stress by itself causes long-term high blood pressure.[2]

\section{MATERIALS AND METHODS}

The study was conducted among the students of saveetha dental college and hospitals, Chennai, India. The study population consists of 60 individuals within the age group of 18-25 years. The students were assessed for change in bloodpressure in two different types of process.

1. Examinations, before their exam the blood pressure were monitored using sphygmomanometer. The process was repeated after their exam using the same sphygmomanometer. (30 individuals).

2. Timely reporting to college, blood pressure were monitored in students who came to college before reporting time i.e, 8:00am using sphygmomanometer and the process was done in students who came after 8:00am to college. (30 individuals).

\section{RESULTS}

The normal blood pressure of human is $120 \mathrm{~mm} \mathrm{hg} \mathrm{systolic}$ and $80 \mathrm{~mm}$ hg diastolic. The blood pressure were recorded in the two different processes.

1. During the first process i.e, before the examination the systolic pressure of the individuals were found to 
be more the $120 \mathrm{~mm} \mathrm{hg}$ and less than $140 \mathrm{~mm} \mathrm{hg}$ and the diastolic pressure were found to be more than $81 \mathrm{~mm} \mathrm{hg}$ and less than $95 \mathrm{~mm}$ hg. There mean difference of the blood pressure was found to be $130 / 86 \mathrm{~mm} \mathrm{hg}$ before examination and after examination it was $120 / 78 \mathrm{~mm}$ h.

2. During the second process, the students who came before the reporting time i.e, 8:00am the systolic pressure were found to be less than $122 \mathrm{~mm} \mathrm{hg}$ and more than $105 \mathrm{~mm} \mathrm{hg}$ and their diastolic pressure was found to be less than $81 \mathrm{~mm} \mathrm{hg}$ and more than $70 \mathrm{~mm} \mathrm{hg}$. The mean difference of the blood pressure was found to be $117 / 78 \mathrm{~mm} \mathrm{hg}$ before and $129 / 84$.

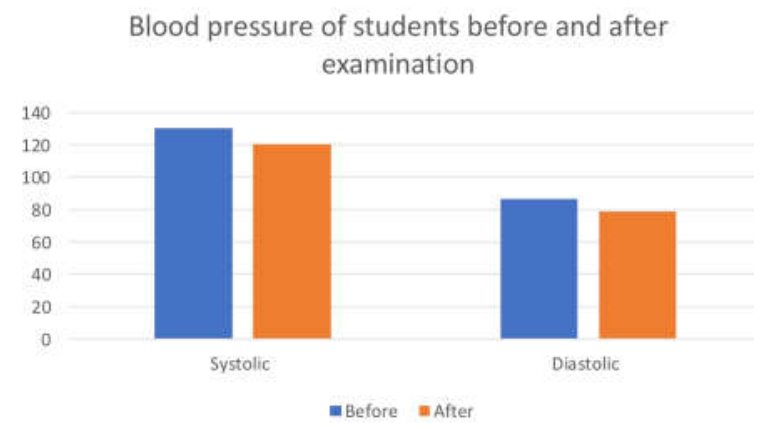

Blood pressure of students who came early and late to college

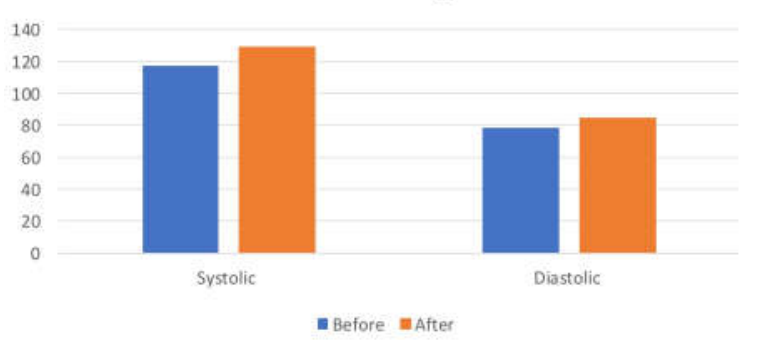

\section{DISCUSSION}

Although the magnitude of effect was relatively small, results suggest the relevance of the control of psychological stress to the non-therapeutic management of high blood pressure. [10] The result shows that, in both the cases time is influenced in their situational stress leading to prehypertension. The blood pressure increased when the individuals feared that they are running out of time.[7] A natural emotional and physical response to any situation where you feel you need to either cope or respond more than usual is termed as stress. Although a stressful situation temporarily raises blood pressure by releasing stress hormones that quicken heart rate and narrow blood vessels, blood pressure eventually returns to normal levels once the stress trigger disappear. [10] But often, stress leads to unhealthy behaviours. Some people deal with stress by overeating and not eating the right foods, smoking or drinking alcohol, or discontinuing physical activity. Factors like obesity and a high-salt diet contribute to hypertension, thus stress has an indirect connection to hypertension.[8] Reducing stress can help lower high blood pressure.[9]
Stress is a normal part of life. But too much stress can lead to emotional, psychological and even physical problems including heart disease, high blood pressure, chest pains or irregular heart beats.[7] If the thought of developing hypertension is stressing you out, visit a doctor and get blood pressure checked. Find out what your blood pressure should be and keep track of it. Manage stress successfully by avoiding unhealthy behaviours do not smoke, limit alcoholic intake, give up junk food, maintain a healthy weight, and also managing time.[2]

\section{CONCLUSION}

Association between time and stress has been established. Stressful events are thought to influence the pathogenesis of physical disease by causing negative affective states (eg, feelings of anxiety and depression), which in turn exert direct effects on biological processes or behavioural pat- terns that influence disease risk.[6] Though time induced stress seems to be normal but this research is to create awareness that short time stress related spikes in the body added up over time lead one at a risk of developing chronic stress and that in-turn leads to long term high blood pressure.so, thereby concluding that it is also necessary to manage time in order to manage stress.

\section{Reference}

1. Cohen S, Janicki-Deverts D, Miller GE. Psychological stress and disease. JAMA. 2007;298:1685-1687

2. Spruill TM. Chronic Psychosocial Stress and Hypertension. Current hypertension reports. 2010; 12(1):10-16. doi:10.1007/s11906-009-0084-8.

3. Cohen S, Janicki-Deverts D, Miller GE. Psychological stress and disease. JAMA. 2007;298:1685-1687

4. Steptoe A, Siegrist J, Kirschbaum C, Marmot C. Effortreward imbalance, overcommitment, and measures of cortisol and blood pressure over the working day. Psychosom Med. 2004;66:323-329

5. Guimont C, Brisson C, Dagenais GR, et al. Effects of job strain on blood pressure: a prospective study of male and female white-collar workers. Am J Public Health. 2006; 96:1436-1439.

6. Sparrenberger F, Cichelero FT, Ascoli AM, et al. Does psychosocial stress cause hypertension? A systematic review of observational studies. J Hum Hypertens. 2009; 23:12-19.

7. Levenstein S, Smith MW, Kaplan GA. Psychosocial predictors of hypertension in men and women. Arch Intern Med. 2001; 161:1341-1346.

8. Kamarck TW, Janicki DL, Shiffman S, et al. Psychosocial demands and ambulatory blood pressure: a field assessment approach. Physiol Behav. 2002; 77:699-704.

9. Vrijkotte TGM, van Doornen LJP, de Geus EJC. Effects of work stress on ambulatory blood pressure, heart rate, and heart rate variability. Hypertension. 2000; 35:880-886.

10. McEwenBS. Protective and damaging effects of stressmediators. N Engl J Med. 1998; 338(3): 171-179. 